\title{
Energy Metabolism Characterization of a Novel Cancer Stem Cell-Like Line 3AB-OS
}

\author{
Roberta Palorini, ${ }^{1,2}$ Giuseppina Votta,${ }^{1,2}$ Chiara Balestrieri, ${ }^{1}$ Andrea Monestiroli, ${ }^{1}$ \\ Sandro Olivieri, ${ }^{1}$ Renza Vento, ${ }^{3,4}$ and Ferdinando Chiaradonna ${ }^{1,2 *}$ \\ ${ }^{1}$ Department of Biotechnology and Biosciences, University of Milano-Bicocca, Piazza della Scienza 2, 20126 Milan, \\ Italy \\ ${ }^{2}$ SYSBIO, Centre for Systems Biology, Piazza della Scienza 2, 20126 Milan, Italy \\ ${ }^{3}$ Section of Biochemical Sciences, Department of Experimental Biomedicine and Clinical Neurosciences, Polyclinic, \\ University of Palermo, Via del Vespro 129 90127, Palermo, Italy \\ ${ }^{4}$ Institute for Cancer Research and Molecular Medicine, Center of Biotechnology-College of Science and \\ Biotechnology, Temple University, Philadelphia, Pennsylvania
}

\begin{abstract}
Cancer stem cells (CSC) have a central role in driving tumor growth. Since metabolism is becoming an important diagnostic and therapeutic target, characterization of CSC line energetic properties is an emerging need. Embryonic and adult stem cells, compared to differentiated cells, exhibit a reduced mitochondrial activity and a stronger dependence on aerobic glycolysis. Here, we aimed to comparatively analyze bioenergetics features of the human osteosarcoma 3AB-OS CSC-like line, and the parental osteosarcoma MG63 cells, from which 3AB-OS cells have been previously selected. Our results suggest that 3AB-OS cells depend on glycolytic metabolism more strongly than MG63 cells. Indeed, growth in glucose shortage or in presence of galactose or pyruvate (mitochondrial specific substrates) leads to a significant reduction of their proliferation compared to MG63 cells. Accordingly, 3AB-OS cells show an increased expression of lactate dehydrogenase A (LDHA) and a larger accumulation of lactate in the culture medium. In line with these findings 3AB-OS cells as compared to MG63 cells present a reduced mitochondrial respiration, a stronger sensitivity to glucose depletion or glycolysis inhibition and a lessened sensitivity to oxidative phosphorylation inhibitors. Additionally, in contrast to MG63 cells, 3AB-OS display fragmented mitochondria, which become networked as they grow in glucose-rich medium, while almost entirely loose these structures growing in low glucose. Overall, our findings suggest that 3AB-OS CSC energy metabolism is more similar to normal stem cells and to cancer cells characterized by a glycolytic anaerobic metabolism. J. Cell. Biochem. 115: 368-379, 2014. @ 2013 Wiley Periodicals, Inc.
\end{abstract}

KEY WORDS: CANCER STEM CELLS; CANCER METABOLISM; WARBURG EFFECT

$\mathrm{U}$ ndifferentiated embryonic stem cells as well as adult stem cells have recently been shown to have a different energetic metabolism as compared to fully differentiated cells. In fact, stem cells rely mostly on anaerobic metabolism rather than on oxidative phosphorylation (OXPHOS) [Varum et al., 2011]. In addition, it has been shown that undifferentiated stem cells have a reduced number of mitochondria, that appear also more immature, a low content of mitochondrial DNA (mtDNA), a reduced oxygen consumption rate and a low level of intracellular adenosine triphosphate (ATP) and reactive oxygen species (ROS) as compared to more differentiated cells [Chen et al., 2008, 2010]. With regard to this, recent observations have correlated energetic cell metabolism to self-renewal and differentiation potential of stem cells. Moreover, human embryonic pluripotent stem cells (hESCs) as well as induced pluripotent stem

Conflict of Interest: The authors declare no conflict of interest.

Grant sponsor: MIUR, PRIN 2008; Grant number: 2008P8BLNF.

The present address of Chiara Balestrieri is Department of Experimental Oncology, European Institute of Oncology (IE0), via Adamello 16 20139, Milan, Italy

${ }^{*}$ Correspondence to: Ferdinando Chiaradonna, Department of Biotechnology and Biosciences, University of MilanoBicocca, Piazza della Scienza 2, 20126 Milan, Italy. E-mail: ferdinando.chiaradonna@unimib.it

Manuscript Received: 30 October 2012; Manuscript Accepted: 6 September 2013

Accepted manuscript online in Wiley Online Library (wileyonlinelibrary.com): 12 September 2013

DOI 10.1002/jcb.24671 • (c) 2013 Wiley Periodicals, Inc. 
cells (iPSCs) show high glycolytic flux [Prigione and Adjaye, 2010; Prigione et al., 2010], while stem cells, that is, embryonic, hematopoietic and mesenchymal, that undergo differentiation, increase mitochondrial biogenesis and function, relying mainly on OXPHOS for energy supply [Chen et al., 2010]. Accordingly, inhibition of mitochondrial respiratory chain, which has recently been found associated with enhancement of hESC pluripotency [Varum et al., 2009] as well as over-expression of mitochondrial protein UCP2 favoring glycolysis, interfere with human PSCs differentiation [Zhang et al., 2011]. Therefore it is becoming clear that energetic metabolism could be used for stem cell recognition and characterization as well as a way of modulating their fate [Chen et al., 2012].

Cancer stem cells (CSCs) or cancer-initiating cells are a population of cells with self-renewal and differentiation capacity, and for this reason they are considered similar to normal stem cells [Tang et al., 2007]. Moreover, CSCs are believed to be fundamental for the promotion and maintenance of several types of cancer as well as for acquiring chemo- and radio-resistance and disease recurrence [O'Brien et al., 2010]. Although our knowledge regarding CSC biology is still limited, the possibility of using a combination of CSCspecific therapeutic approaches with traditional cancer treatment strategies is rapidly growing [Clarke and Becker, 2006; Clarke et al., 2006; Diehn and Clarke, 2006]. Indeed, current therapies preferentially kill differentiated cancer cells, which eventually may result in preservation and enrichment of CSCs [Cheng et al., 2011]. Thus, a better understanding of CSC biology is becoming urgent to provide therapies able to offer significant clinical benefit.

To date, several observations have indicated that genetic alterations that are known to promote cancer lead also to the reorganization of cell metabolism in order to enhance cellautonomous nutrient uptake and support biosynthesis. In particular it has been shown that cancer cells use more glucose compared to normal cells and accumulate extracellular lactate even in normoxic conditions, a feature called Warburg effect [Chiaradonna et al., 2012; Ward and Thompson, 2012]. In addition, cancer cells often present a limited or absent mitochondrial OXPHOS, probably caused by a block in mitochondrial biogenesis, mtDNA mutations and gene expression deregulation [Chiaradonna et al., 2012; Ward and Thompson, 2012]. Given that, cancer cell metabolism is being extensively used for noninvasive diagnostic purposes in several human tumor types, through the use of positron emission tomography (PET), and is also a promising approach for cancer therapy. To date, energy metabolism in CSCs remains to be explored. In fact, it is unknown whether the metabolic profile of CSCs is similar to that observed in embryonic stem cells and whether it is able to originate the alterations observed in somatic cancer cells. Since recent observations indicate a link between cellular metabolism and cellular differentiation and since cancer stem cells induced to differentiate become less tumorigenic, that is, as a consequence of a reduced proliferation [Beug, 2009; Varum et al., 2009; Zhang et al., 2011], manipulation of cell metabolism for possible therapeutic targets in tumors is very intriguing.

So far, the main limitations in studying CSC biology have been their identification, characterization, isolation and mostly important the fact that they are only a small fraction of the total cancer cells.
Therefore an attractive alternative source of cells for CSC research has been the identification and isolation of established cancer stem cell subpopulation from cancer cells that retain stem cell patterns of behavior. Nowadays, CSCs have been successfully separated from cell lines derived from various solid cancers including glioma [Qiang et al., 2009], breast cancer [Fillmore and Kuperwasser, 2008], lung cancer [Ho et al., 2007], head and neck squamous carcinoma [Huang et al., 2009].

Herein we take advantage of a stable CSC-like line, namely 3ABOS, derived from a human osteosarcoma cell line MG63 [Di Fiore et al., 2009]. This CSC-like line have been shown to express a number of pluripotent embryonic and mesenchyme stem cell marker genes [Di Fiore et al., 2009, 2013] and, as confirmed by a transcriptional profiling in comparison with MG63, an enrichment of different pathways involved in the maintenance of stemness phenotype [Di Fiore et al., 2013]. Its plurilineage differentiation potential has been demonstrated in vitro, with the production of derivatives of the three primary germ layers: endoderm, mesoderm, and ectoderm [Di Fiore et al., 2013]. Moreover, when injected in athymic mice, these cells recapitulate various features of human osteosarcoma [Di Fiore et al., 2012]. Noteworthy is the fact that such a stem-like phenotype, both in terms of morphological and antigenic features, is retained after prolonged serial passages (up to now, more than 200 passages) (unpublished observations). In our study we show that $3 \mathrm{AB}-\mathrm{OS}$ cells rely on glycolysis to sustain their proliferation and survival. Indeed, glucose deprivation and glycolysis inhibition induce their proliferation arrest and death. Importantly, analysis of some mitochondrial parameters, like respiration rate, mitochondrial genes expression, OXPHOS-dependent ATP production and mitochondrial morphology, indicate that they are more similar either to normal stem cells or to cancer cells characterized by a glycolytic anaerobic metabolism.

\section{MATERIALS AND METHODS}

\section{CELL CULTURES}

Human osteosarcoma MG63 cells and 3AB-OS stem cells [Di Fiore et al., 2009] were routinely cultured in Dulbecco's modified Eagle's medium (DMEM) containing $4 \mathrm{mM} \mathrm{L-glutamine,} 100 \mathrm{U} / \mathrm{ml}$ penicillin and $100 \mathrm{mg} / \mathrm{ml}$ streptomycin (complete medium), supplemented with $10 \%$ Fetal Bovine Serum. All reagents for media were purchased from Life Technologies (Carlsbad, CA).

\section{CELL ANALYSES AND TREATMENTS}

Cells were plated at the density of 12,500 cells $/ \mathrm{cm}^{2}$ in complete growth medium. After $16 \mathrm{~h}$ cells were washed twice with phosphate buffer saline (PBS) and incubated in growth medium (time 0) without glucose and sodium pyruvate (Life Technologies), supplemented with 25 or 1 or $0.25 \mathrm{mM}$ glucose, $25 \mathrm{mM}$ galactose, $10 \mathrm{mM}$ methylpyruvate, $25 \mathrm{mM}$ glucose supplemented with 5 or $10 \mathrm{mg} / \mathrm{ml}$ oxamate. Glucose, galactose, methyl-pyruvate and oxamate were purchased from Sigma-Aldrich, Inc. (St. Louis, M0). For some specific analyses, cells at time 0 were incubated in growth medium with $25 \mathrm{mM}$ glucose supplemented with 4 or $0.5 \mathrm{mM}$ glutamine (Life Technologies). Cells were then collected for further analyses at $24,48,72 \mathrm{~h}$ of culture. When indicated, viable cell count was performed using Trypan Blue Stain $0.4 \%$ (Life Technologies). 


\section{D-GLUCOSE AND LACTATE MEASUREMENT}

D-Glucose and L-Lactate levels in culture medium were determined using spectrophotometric enzyme assay kits (R-Biopharm, Darmstadt, Germany) as specified by manufacturer's datasheet.

\section{FLOW CYTOMETRIC ANALYSES}

Cell death and glucose uptake analyses were carried out through flow cytometric analyses using a FACScan flow cytometer (BectonDickinson, Franklin Lakes, NJ) with CellQuest software (BectonDickinson). Cell death was analyzed by staining cells with Annexin V-FITC and propidium iodide (PI) through the Apoptosis assay kit from Immunological Sciences (Rome, Italy). Glucose uptake assay was performed using 2-[N-(7-nitrobenz-2-oxa-1,3-diazol-4-yl) amino]-2-deoxy-D-glucose (2-NBDG; Life Technologies) fluorescent glucose analogue as described in Palorini et al. [2013]. Analysis of flow cytometric data was carried out using WinMDI software (freely available).

\section{INTRACELLULAR ATP ANALYSIS}

Intracellular ATP levels were measured using CellTiter Glo ${ }^{\circledR}$ luciferinluciferase assay (Promega, Madison, WI) as described in Chiaradonna et al. [2006b]. Where indicated, intracellular ATP levels were measured after 1 or $2 \mathrm{~h}$ cell treatment with $5 \mu \mathrm{M}$ oligomycin (Sigma-Aldrich) or $3 \mathrm{nM}$ rotenone (Sigma-Aldrich).

\section{OXYGEN CONSUMPTION RATE (OCR) ANALYSIS}

Oxygen consumption was determined using Seahorse XF24 extracellular Flux analyzer (Seahorse Bioscience, North Billerica, MA). Briefly, cells for the analysis were seeded in a dedicated 24-well XF24 cell culture plate in a complete medium. Then, $1 \mathrm{~h}$ before the analysis, this culture medium was exchanged for a specific base medium (unbuffered DMEM supplemented with $25 \mathrm{mM}$ glucose and $2 \mathrm{mM}$ sodium pyruvate) to be used along all the experiment. Different compounds were added in succession: oligomycin $(1 \mu \mathrm{M})$, carbonyl cyanide 4-(trifluoromethoxy)phenylhydrazone (FCCP) $(0.9 \mu \mathrm{M})$ and rotenone $(1 \mu \mathrm{M})$ plus antimycin $\mathrm{A}(1 \mu \mathrm{M})$. The compounds were purchased as XF Cell Mito Stress Test kit from Seahorse Bioscience. After the analysis the cells were fixed, stained with Crystal Violet and dosed at spectrophotometer after colorant solubilization with acetic acid 10\%; all OCR values obtained by the instrument were normalized on cell density. Due to some variations in the absolute magnitude of OCR measurements in different experiments, the relative OCR levels were used to compare and summarize independent biological replicates. Coupling efficiency and spare respiratory capacity were calculated as 1 minus (response to oligomycin/basal respiration) and response to $\mathrm{FCCP} /$ basal respiration, respectively. Response to oligomycin represents the minimum rate after oligomycin injection; response to FCCP represents the maximum rate after FCCP injection; basal respiration is the third basal measurement (before the first injection).

\section{OXPHOS COMPLEX I ACTIVITY DETERMINATION}

To determine the complex I activity the Complex I Enzyme Activity Microplate Assay kit from Abcam (Cambridge, UK) was used. The analysis was performed following manufacturer's datasheet and using for each determination $0.6 \mathrm{mg}$ of whole culture cell extract.

\section{GENE EXPRESSION ANALYSIS BY qPCR}

RNA was extracted from cells using Trizol reagent (Life Technologies Corporation). Total RNA was reverse transcribed with oligo dT by using the Superscript ${ }^{\mathrm{TM}}$ III RT-PCR First Strand Synthesis System for RT PCR (Life Technologies Corporation). $0.2 \mu \mathrm{g}$ of the RT product was amplified by real-time quantitative PCR (qPCR) with an Applied Biosystem 7500 standard system (Life Technologies Corporation) using POWER SYBR GREEN PCR mix for qPCR (Life Technologies Corporation). Primers were designed using Primer3Plus software (http://www.bioinformatics.nl/cgi-in/primer3plus/primer3plus.cgi) and used at $0.25 \mu \mathrm{M}$. The analysis was performed for some glycolytic genes (GLUT1, HKII, LDHA), Complex I genes (NDUFA9, GRIM19, and ND1), Complex IV genes (COXI, COXII, COXIII, and COXIV) and Complex $\mathrm{V}$ genes (ATP5B and ATP6). As internal control of PCR assays specific primers for beta-actin transcript were designed. Primers: GLUT1: forward CTCCCCACACACACAAAA, reverse CCAAATCGGCATCTTCTCAT; HKII: forward TAGGGCTTGAGAGCACCTGT, reverse CCACACCCACTGTCACTTTG; LDHA: forward TGTGCCTGTATGGAGTGGAA, reverse AGCACTCTAACCACCTGCT; NDUFA9: forward CAGATTGTTCCTCCCATTCC, reverse TGCATCCGCTCCACTTTATC; GRIM19: forward AGATGCTTCGGGAGAACCTG, reverse GGCCTACGTGTACCACATGA; ND1: forward CCCTGGTCAACCTCAACCTA, reverse CTAGTTCGGACTCCCCTTCG; COXI: forward ACGTTGTAGCCCACTTCCAC, reverse AGCGAAGGCTTCTCAAATCA; COXII: forward TAACATCTCAGACGCTCAGGAA, reverse GTTGAAGATTAGTCCGCCGTAG; COXIII: forward AAATCCCCTAGAAGTCCCACTC, reverse CTCTGAGGCTTGTAGGAGGGTA; COXIV: forward TTCGCTCCCAGCTTATATGG, reverse GCTTCTGCCACATGATAACG; ATP5B: forward TTGCTATGGATGGTACAGAAGG, reverse TTTGGTTTTGATGGGACCTC; ATP6: forward TATTGATCCCCACCTCCAAA, reverse GATGGCCATGGCTAGGTTTA; ACTIN B: forward TCATGAAGTGTGACGTTGACA, reverse CCTAGAAGCATTTGCGGTGCAC.

\section{WESTERN BLOT}

For the analysis of glycolytic proteins, cells were harvested and lysed in JS buffer ( $50 \mathrm{mM}$ Hepes $\mathrm{pH} 7.5,150 \mathrm{mM} \mathrm{NaCl}, 1 \%$ glycerol; $1 \%$ triton X-100, $1.5 \mathrm{mM} \mathrm{MgCl}$, $5 \mathrm{mM} \mathrm{EGTA).} \mathrm{For} \mathrm{each} \mathrm{sample} \mathrm{an} \mathrm{equal}$ amount of the whole extract was then resolved by sodium dodecyl sulfate polyacrylamide gel electrophoresis and transferred to nitrocellulose membrane, which was incubated overnight with antibodies for GLUT1 (Santa Cruz Biotechnology, Inc., Santa Cruz, CA), HKII and Actin B (Cell Signaling Technology, Inc., Danvers, MA) and LDHA (CHEMICON by EMD Millipore Corporation, Billerica, MA).

\section{MITOCHONDRIAL MORPHOLOGY ANALYSIS}

To study mitochondrial morphology, stable cell clones of MG63 and 3AB-0S, expressing a pEYFP-Mito fusion protein (6115-1, BD Biosciences, Franklin Lakes, NJ) were isolated and used for the morphological experiments. Images of mitochondrial morphology were collected under a Nikon ECLIPSE 90i fluorescence microscope (Nikon, Tokyo, Japan) equipped with a b/w CCD camera (HamamatsuCoolSnap, Hamamatsu Corporation, Japan). Images were then visualized, processed and classified by using ImageJ software. 


\section{AB-OS CANCER STEM CELLS ARE STRONGLY DEPENDENT ON} GLUCOSE AVAILABILITY FOR CELL PROLIFERATION AND SURVIVAL

As reported by several Authors, cancer cells are more susceptible, in terms of proliferation and cell death, to glucose (Glc) or glutamine (Gln) withdrawal as compared to normal counterparts [Chiaradonna et al., 2006b; Yuneva et al., 2007]. Thus, we decided to analyze cell proliferation of the MG63 and 3AB-OS cell lines in different initial glucose and glutamine concentrations: normal glucose and glutamine condition ( $25 \mathrm{mM}$ Glc plus $4 \mathrm{mM} \mathrm{Gln}$ ); low glucose condition (1 or $0.25 \mathrm{mM}$ Glc plus $4 \mathrm{mM} \mathrm{Gln}$ ); low glutamine condition (25 mM Glc plus $0.5 \mathrm{mM} \mathrm{Gln}$ ). Although glucose shortage halted proliferation in both cell lines, as shown by cell counting (Fig. 1A,B), it induced specifically cell death in $3 \mathrm{AB}-\mathrm{OS}$ cells, as shown by microscopy observation (floating rounded cells are seen) (Fig. 1C), Trypan Blue vital stain (Fig. 1D,E) and Annexin V/PI staining followed by FACS analysis (Fig. 1F,G). In particular, the latter analysis, performed at $72 \mathrm{~h}$ of growth in low glucose, indicated a threefold increase of percentage of cell death in 3AB-OS cells as compared to MG63 (42.3\% vs. 13.5\%, upper right and left quadrants and lower right quadrant). Importantly, such an increase of cell death was appreciably glucosedependent only in $3 \mathrm{AB}-\mathrm{OS}$ cells, since the percentage measured at normal glucose was 11.1\% in this cell line and 6.1\% in MG-63 cells. To certainly correlate the effects on cell proliferation and survival to glucose withdrawal, we measured the residual glucose in the low glucose culture medium along a time course of $72 \mathrm{~h}$. As shown in Supplementary Figure 1, both cell lines utilized all the glucose present in the medium in $24 \mathrm{~h}$, suggesting that after that time they had to use different substrates for their anabolic and energetic needs.

Several studies have reported that glucose deprivation can lead to ATP depletion leading cell death [Chiaradonna et al., 2006b; Kim et al., 2007; Sandulache et al., 2011; Palorini et al., 2013]. Therefore we determined the levels of ATP in both cell lines grown in the normal condition and in glucose shortage along a time course of $72 \mathrm{~h}$. Overall, slightly higher ATP levels were observed in MG63 cells as compared to $3 \mathrm{AB}-0 \mathrm{~S}$ cells along the time course (Fig. $1 \mathrm{H})$. In particular, at the later time point of low glucose growth $(72 \mathrm{~h})$, in correlation with the appearance of cell death, $3 \mathrm{AB}-0 \mathrm{~S}$ cells showed a significant decrease in ATP levels as compared to the high glucose condition and to MG63 cells grown in the same glucose availability (Fig. 1H). Notably, all the glucose-dependent effects observed in $3 \mathrm{AB}-0 \mathrm{~S}$ cells were further increased at $96 \mathrm{~h}$ of culture (data not shown) underlining the important role of the glucose in CSC physiology.

Since many cancer cells depend on glutamine as a fuel for growth, we also tested the effect of glutamine reduction on both cell line proliferation. As shown in Supplementary Figure 2, glutamine withdrawal induced a slight decrease of proliferation only in MG63 cells at $72 \mathrm{~h}$ of culture.

Altogether these findings suggest that $3 \mathrm{AB}-0 \mathrm{~S}$ cells are strongly dependent on glucose availability for their proliferation and survival as compared to MG63 cells. In addition we observe that MG63 cells are more sensitive to glutamine deprivation, indicating that glutamine is much critical for their growth as compared to $3 \mathrm{AB}-\mathrm{OS}$ cells.

\section{LACTATE DEHYDROGENASE INHIBITION ROBUSTLY AFFECTS 3AB-OS PROLIFERATION AND SURVIVAL}

In order to investigate whether the $3 \mathrm{AB}-0 \mathrm{~S}$ proliferation arrest and death in low glucose could be a consequence of alterations in glucose metabolism, we assessed several glycolytic parameters by measuring the glucose transport rate into the cells, glucose consumption and lactate production, the mRNA and protein expression of some glycolytic proteins and the effects of the treatment with oxamate, a known lactate dehydrogenase A (LDHA) inhibitor. Glucose uptake rate was measured by using the fluorescent derivative of glucose 2NBDG as indicator. Such an analysis, performed on cells grown for $24 \mathrm{~h}$ of culture in high glucose condition, indicated a slightly faster uptake in MG63 cells as compared to 3AB-OS (Fig. 2A). To further detail the glycolytic capacity of both cell lines, glucose utilization and lactate production in cells grown at high glucose availability were assayed. As shown in Figure 2B, the amount of consumed glucose per cell, at both 24 and $72 \mathrm{~h}$ of culture, was substantially comparable between the two cell lines; however, 3AB-OS cells produced, at both time points, a larger amount of lactate as compared to MG63 cells (Fig. 2C). To investigate whether the different fate of glucose, as indicated by the increased lactate production of 3AB-OS cells, could be associated with a different expression of glycolytic proteins in the two cell lines, we measured both mRNA and protein expression levels of the glucose transporter GLUT1, of the enzyme catalyzing the first glycolytic step, namely Hexokinase II (HKII) and of the pyruvatelactate converting enzyme LDHA. As shown in Supplementary Figure 3, the mRNA level of HKII was higher in 3AB-OS cells. No difference in GLUT1 mRNA expression was observed between the two cell lines. Conversely, GLUT1 protein was higher expressed in 3AB-OS cells as compared to MG63 and no difference in HKII protein expression was observed (Supplementary Figure 3). Notably, a clear increase of LDHA mRNA and protein expression in $3 \mathrm{AB}-0 \mathrm{~S}$ cells as compared to MG63 was observed (Fig. 2D). Since the key glycolytic enzyme LDHA was highly expressed in $3 \mathrm{AB}-0 \mathrm{~S}$ cells we sought to determine if $3 \mathrm{AB}-0 \mathrm{~S}$ cells proliferation and survival could be altered by inhibiting LDHA activity using oxamate, a structural analog of pyruvate that acts as competitive inhibitor of LDHA. As shown in Figure 2E, F, oxamate addition to the culture medium induced in $3 \mathrm{AB}-0 \mathrm{~S}$ cells a time- and dose-dependent cell death process that was not observed in MG63 cells.

Thus, these data show that 3AB-OS cells, despite the similar glucose consumption and the slightly lower rate of glucose uptake as compared to MG63 cells, are fundamentally dependent on glucose fermentation for proliferation and survival. In addition, the data underline the ability of MG63 cells to activate other metabolic processes, that is, oxidative phosphorylation, that guarantee their survival under glucose shortage.

\section{AB-OS CELLS SHOW REDUCED MITOCHONDRIAL RESPIRATION AND COMPLEX I ACTIVITY AS COMPARED TO MG63 CELLS ASSOCIATED TO LIMITED ALTERATIONS OF mRNA EXPRESSION OF OXPHOS GENES}

To test whether high sensitivity to aerobic glycolysis inhibition in $3 \mathrm{AB}-0 \mathrm{~S}$ cells is a consequence of a reduced mitochondrial activity, we assessed the ability of both cell lines to grow in media containing galactose or pyruvate. In fact, both substrates in a glucose-free 


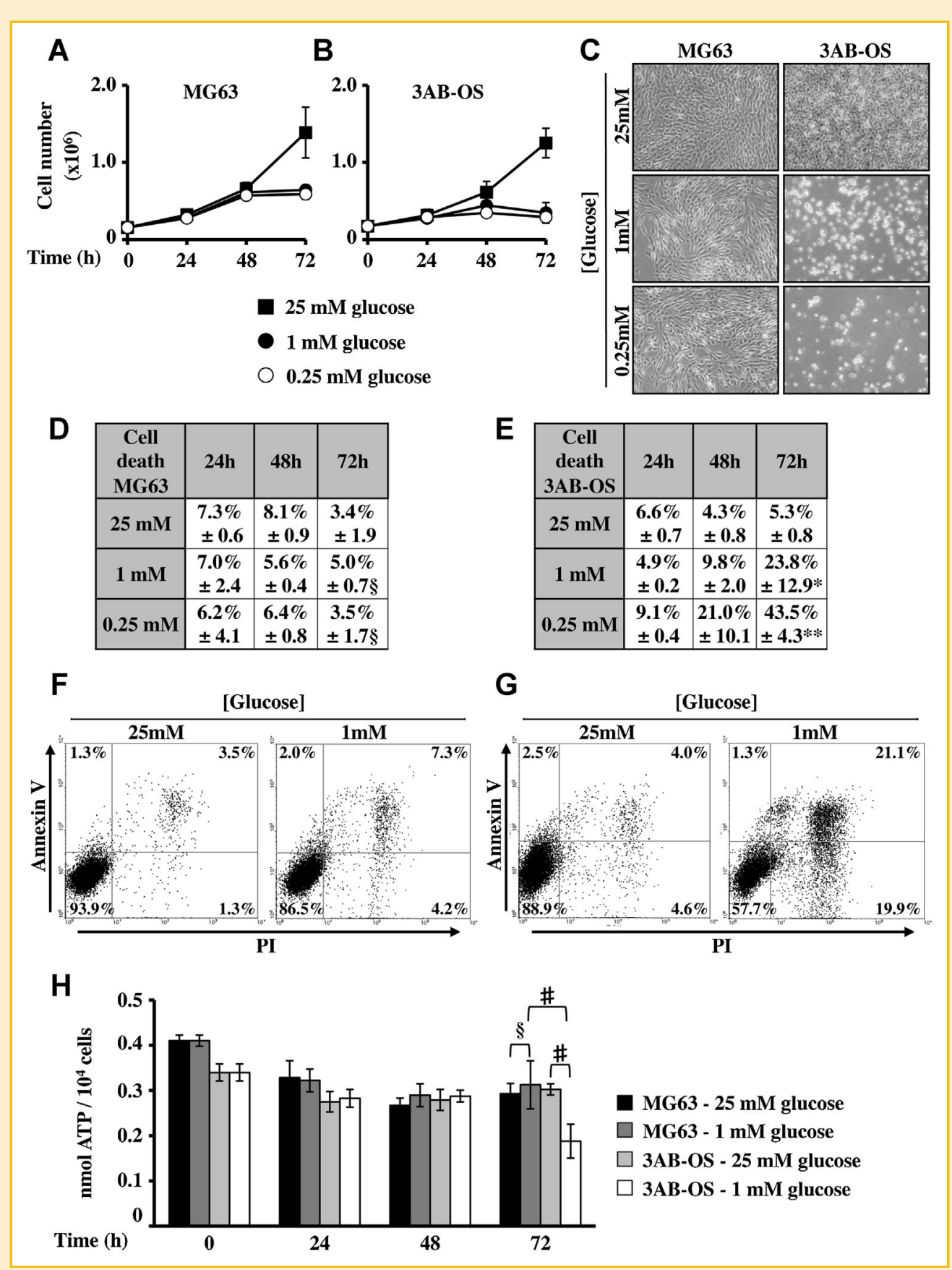

Fig. 1. Glucose deprivation leads to $3 A B-O S$ cell proliferation arrest and death associated with intracellular ATP depletion. Proliferation curves of $M G 63$ ( $A$ ) and $3 A B-0 S$ ( $B$ ) cells cultured at 25,1 , or $0.25 \mathrm{mM}$ glucose were determined counting cells at indicated time points. $C$ : Phase contrast microscopy images were collected for $M G 63$ and $3 A B-0 S$ cells at $72 \mathrm{~h}$ of cell culture. D,E: The percentage of MG63 (D) and $3 A B-O S$ (E) cell death at the different culture conditions was evaluated by using Trypan Blue Stain; ${ }^{*} P<0.05$, ${ }^{* *} P<0.01$ and § not significant (Student's t-test), compared to $25 \mathrm{mM}$ glucose. F,G: Apoptosis was also evaluated at $72 \mathrm{~h}$ of culture by staining MG63 (F) and $3 \mathrm{AB}-0 \mathrm{~S}$ (G) cells with Annexin V-FITC and PI. Representative dot plots are shown. H: Also total intracellular ATP was measured in both cell lines; ${ }^{\#} P<0.001$ and $\S$ not significant (Student's $t$-test). All data represent the average of at least three independent experiments ( \pm SD).

medium would favor mitochondrial oxidative respiration over glycolysis. MG63 cells, grown in media containing $1 \mathrm{mM}$ glucose, $25 \mathrm{mM}$ galactose or $10 \mathrm{mM}$ methyl-pyruvate, exhibited a similar rate of proliferation (Fig. 3A,C,D). Conversely, galactose- and pyruvateenriched growth media further decreased $3 \mathrm{AB}-\mathrm{OS}$ proliferation, as compared to low glucose, since an early reduction in the slope of the growth curve $(24 \mathrm{~h})$ was observed (Fig. 3B-D). To measure the fraction of total ATP generated by mitochondrial OXPHOS under the prevailing cultivation conditions, the cells were treated with oligomycin, a specific inhibitor of the mitochondrial $\mathrm{F}_{\mathrm{o}} \mathrm{F}_{1}$ ATP 


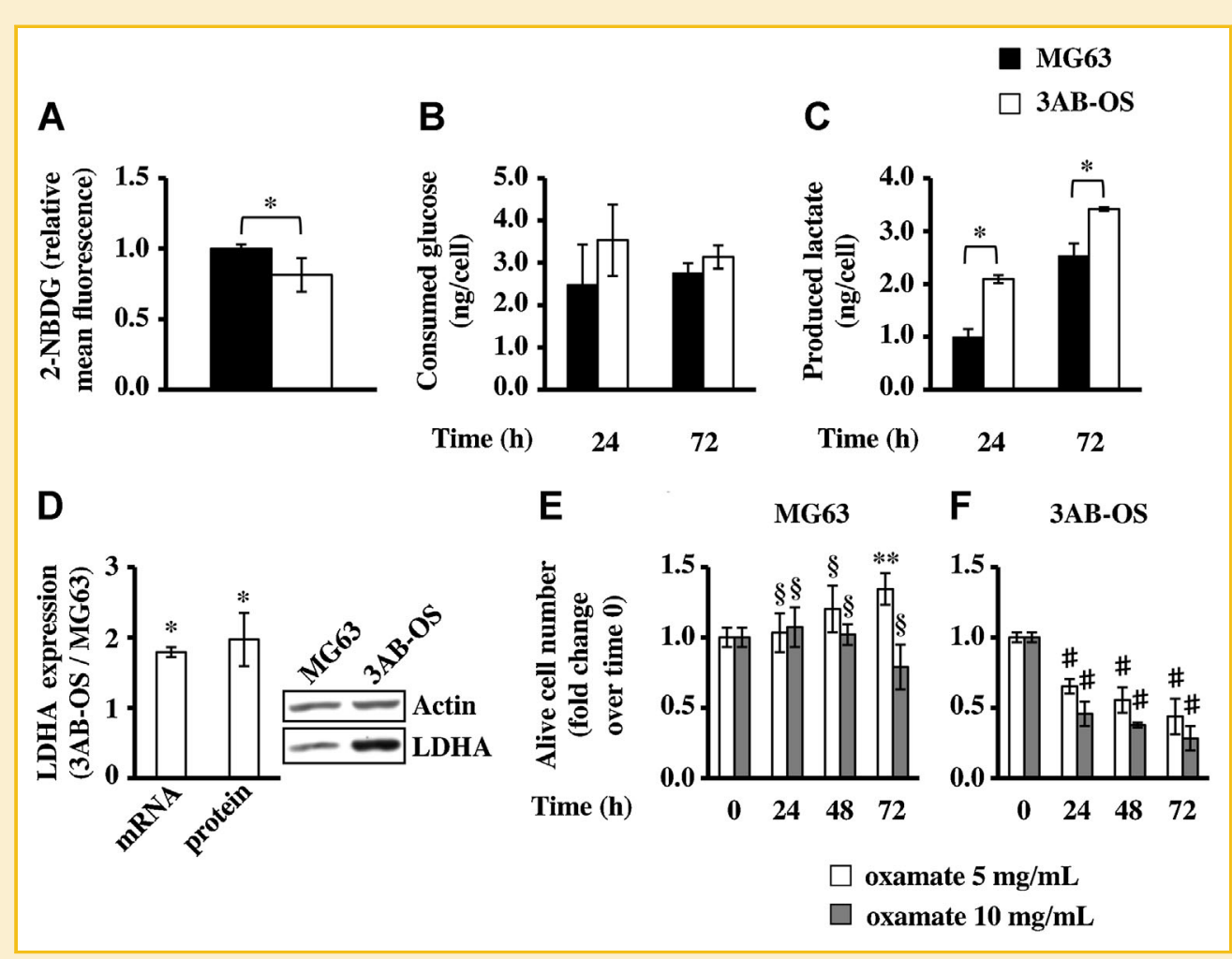

Fig. 2. Higher expression of LDHA in $3 A B-O S$ cells leads to a major use of glucose through fermentation rather than through OXPHOS. A: Glucose uptake rate was determined by using the fluorescent glucose analogue $2-N B D G$ at $24 \mathrm{~h}$ of culture; ${ }^{*} P<0.05$ (Student's $t$-test). B,C: Residual glucose (B) and secreted lactate (C) in the culture medium of MG63 and $3 A B-O S$ cells, grown at $25 \mathrm{mM}$ initial glucose concentration, were measured by using specific enzymatic kits. The obtained values were used to calculate the consumed glucose and the produced lactate per cell at indicated time points; ${ }^{*} P<0.05$ (Student's $t$-test). D: mRNA and protein expression of Lactate dehydrogenase $A$ (LDHA) in MG63 and $3 A B-O S$ cells was determined by real-time qPCR and Western blot, respectively. mRNA expression levels in 3AB-OS cells are reported as change ( $n$-fold) with respect to the amount of relative mRNA expressed in MG63 cells, using beta-actin mRNA as an internal control. Protein level in $3 A B-0 S$ is reported as fold change over the expression level in MG63 cells, using Actin for the normalization. On the right a representative image of the Western blot is reported. ${ }^{*} \boldsymbol{P}<0.05$ (Student's $t$-test). E,F: MG63 (E) and $3 A B-0 S$ (F) cells were cultured at $25 \mathrm{mM}$ glucose in presence of the glycolysis inhibitor oxamate and counted at the indicated time points using Trypan Blue Stain. In the histograms the number of alive cells at each time point is represented as fold change over time $0 ;{ }^{* *} P<0.01,{ }^{\#} P<0.001$ and $\S$ not significant (Student's $t$-test), compared to time 0 . All data represent the average of three independent experiments $( \pm S D)$.

synthase, and rotenone, a mitochondrial Complex I inhibitor. The addition of oligomycin and rotenone respectively reduced the intracellular ATP level of MG63 cells by around 15\% and 12\% in $1 \mathrm{~h}$ and 26\% and 20\% in $2 \mathrm{~h}$ (Fig. 3E,G). In 3AB-OS cells, cultivated in the same condition, oligomycin and rotenone addition did not exert a major inhibitory effect on cellular ATP levels (around 5\% for both) as compared to MG63 cells (Fig. 3F,G) and as compared to the oxamate effect (data not shown). These findings show that in $3 \mathrm{AB}-0 \mathrm{~S}$ cells the mitochondrial OXPHOS contributes only marginally to cellular ATP production, which is essentially contributed by glycolysis. Altogether these findings confirm the low functioning of 3AB-OS mitochondria, resulting in the inability to grow on specific respiratory substrates as compared to MG63 cells.

To directly determine the mitochondrial activity of $3 \mathrm{AB}-0 \mathrm{~S}$ cells compared to MG63 cells we performed the analysis of the oxygen consumption rate (OCR) using the Seahorse XF24 extracellular flux analyzer. In particular, we determined a response profile to specific compounds that are able to shift cell bioenergetics. The complete profile confirmed that $3 \mathrm{AB}-\mathrm{OS}$ cells have reduced mitochondrial respiration as compared with MG63 (Fig. 4A). In fact, 3AB-OS cells showed a lower coupling efficiency (Fig. 4B), calculated after the treatment with oligomycin, and lower spare respiratory capacity (the maximal capacity of the mitochondrial OXPHOS), calculated after the treatment with FCCP (Fig. 4C). Both parameters are a distinct indication of a lower mitochondrial activity in $3 \mathrm{AB}-0 \mathrm{~S}$ cells as compared to MG63 ones.

Since several authors have shown in different cancer cells a relation between mitochondrial dysfunction and alteration in the levels of expression of nuclear or mitochondrial genes encoding for OXPHOS complexes [Park et al., 2009; Gasparre et al., 2011] or reduction of Complex I activity [Baracca et al., 2010], we specifically determined the enzymatic activity of Complex I and the level of expression of some mRNAs encoding for mitochondrial Complex I, $\mathrm{IV}$, and $\mathrm{V}$ subunits in both cell lines.

As shown in Figure 4D, 3AB-OS cells, in line with their reduced OCR value, showed also a reduction of Complex I activity of about 40\% as compared to MG63 cells. Surprisingly, despite the strong reduction of Complex I activity, two on three mRNA encoding for 


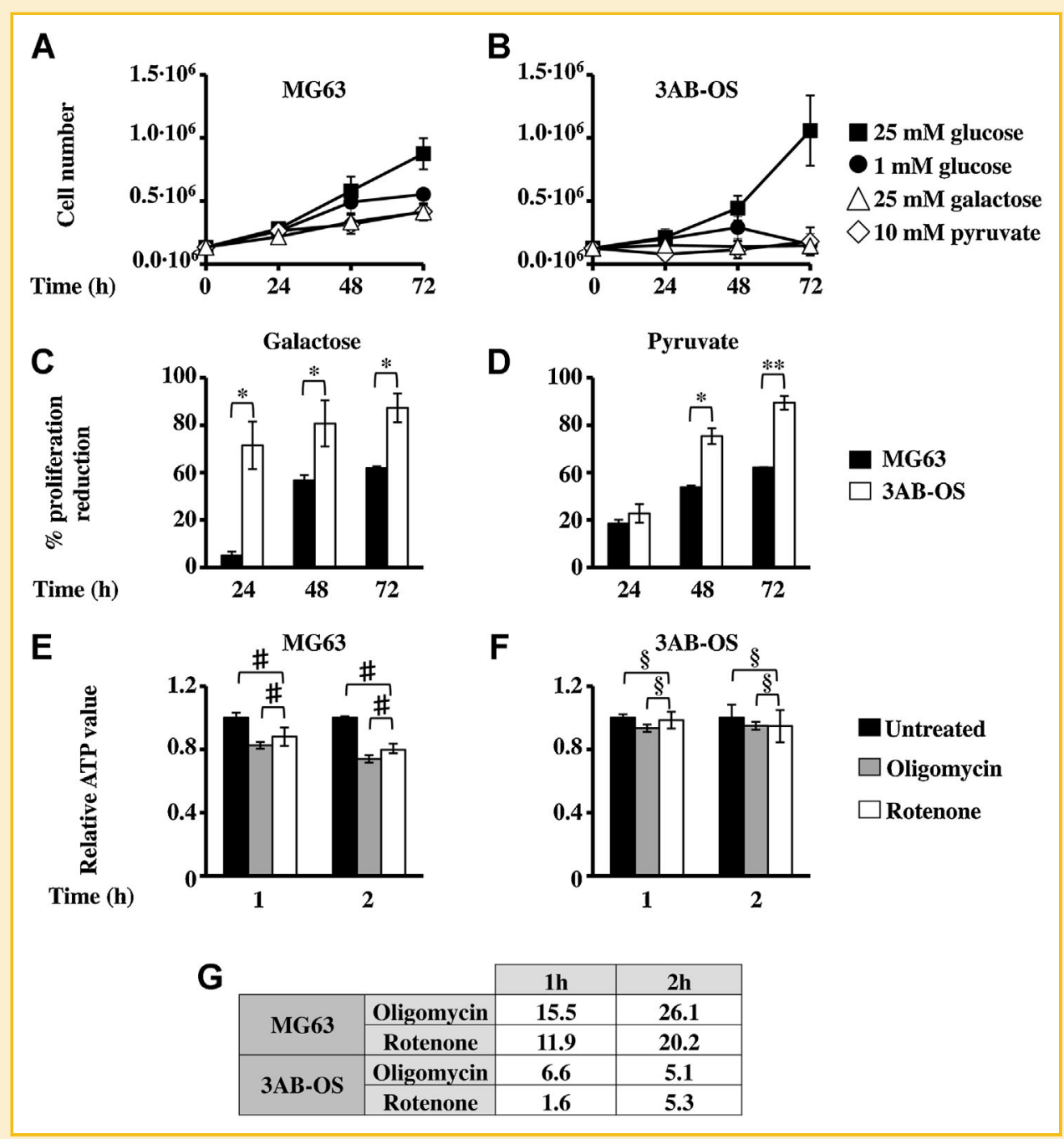

Fig. 3. $3 A B-O S$ cells are unable to proliferate in presence of respiratory substrates. Proliferation curves of $M G 63(A)$ and $3 A B-O S$ (B) cells cultured at $25 \mathrm{mM}$ glucose (Glc), at $1 \mathrm{mM} \mathrm{Glc}$, at $25 \mathrm{mM}$ galactose (Gal) or $10 \mathrm{mM}$ methyl-pyruvate (Pyr) were determined counting cells at the indicated time points. C,D: Percentages of proliferation reduction in $25 \mathrm{mM}$ Gal (C) and $10 \mathrm{mM}$ Pyr (D) as compared with $25 \mathrm{mM}$ Glc at each time point for both cell lines. E,F: Total intracellular ATP levels were measured in MG63 (E) and 3 AB-0S (F) cells grown for $24 \mathrm{~h}$ at $25 \mathrm{mM} \mathrm{Glc}$, treated or not with $5 \mu \mathrm{M}$ oligomycin or $3 \mathrm{nM}$ rotenone for 1 or $2 \mathrm{~h}$. Values are relative to untreated samples. G: Percentage of ATP reduction as compared to untreated samples for both cell lines upon the above treatments. All data represent the average of at least three independent experiments $( \pm S D) ;{ }^{*} P<0.05$, ${ }^{* *} P<0.01,{ }^{\# P}<0.001$ and $\S$ not significant (Student's $t$-test).

Complex I subunits (NDUF9 and ND1 vs. GRIM19) were strongly overexpressed in 3AB-OS cells as compared to MG63 ones (Fig. 4E). On the contrary, no significant differences between the two cell lines in the expression levels of the Complex IV (COX I, COX II, COX III, and $C O X I V)$ and Complex V (ATP5B and ATP6) tested mRNAs were observed (Fig. 4E).

\section{AB-OS CELLS SHOW MORE FRAGMENTED MITOCHONDRIAL MORPHOLOGY ESPECIALLY UPON NUTRIENT DEPLETION}

Mitochondria are dynamic organelles that mediate several cell functions. Depending on the cellular context, mitochondria may shift between fragmented and networked structure by means of coordinated fission and fusion [Westermann, 2010]. Given that, it has been shown that interconnected mitochondria are functionally more active than fragmented mitochondria [Mitra et al., 2009; Gomes et al., 2011]. Therefore we sought to determine mitochondrial morphology of both cell lines, along a time-course in normal growth conditions and in low glucose, that is known to induce mitochondrial elongation [Rambold et al., 2011; Palorini et al., 2013].

Mitochondrial morphology was analyzed by means of stable clones of both cell lines expressing a mitochondrially targeted EYFPMito protein (Fig. 5A). Three types of mitochondrial morphologies have been classified as fragmented, intermediate and networked (Fig. 5A). At an early growth time (0-24 h), MG63 cells displayed especially networked and intermediate mitochondria regardless of initial glucose concentrations (Fig. 5B). At a later growth time (72 h), mitochondrial morphology was strictly associated with glucose availability. In fact, in glucose rich medium, MG63 cells showed a 


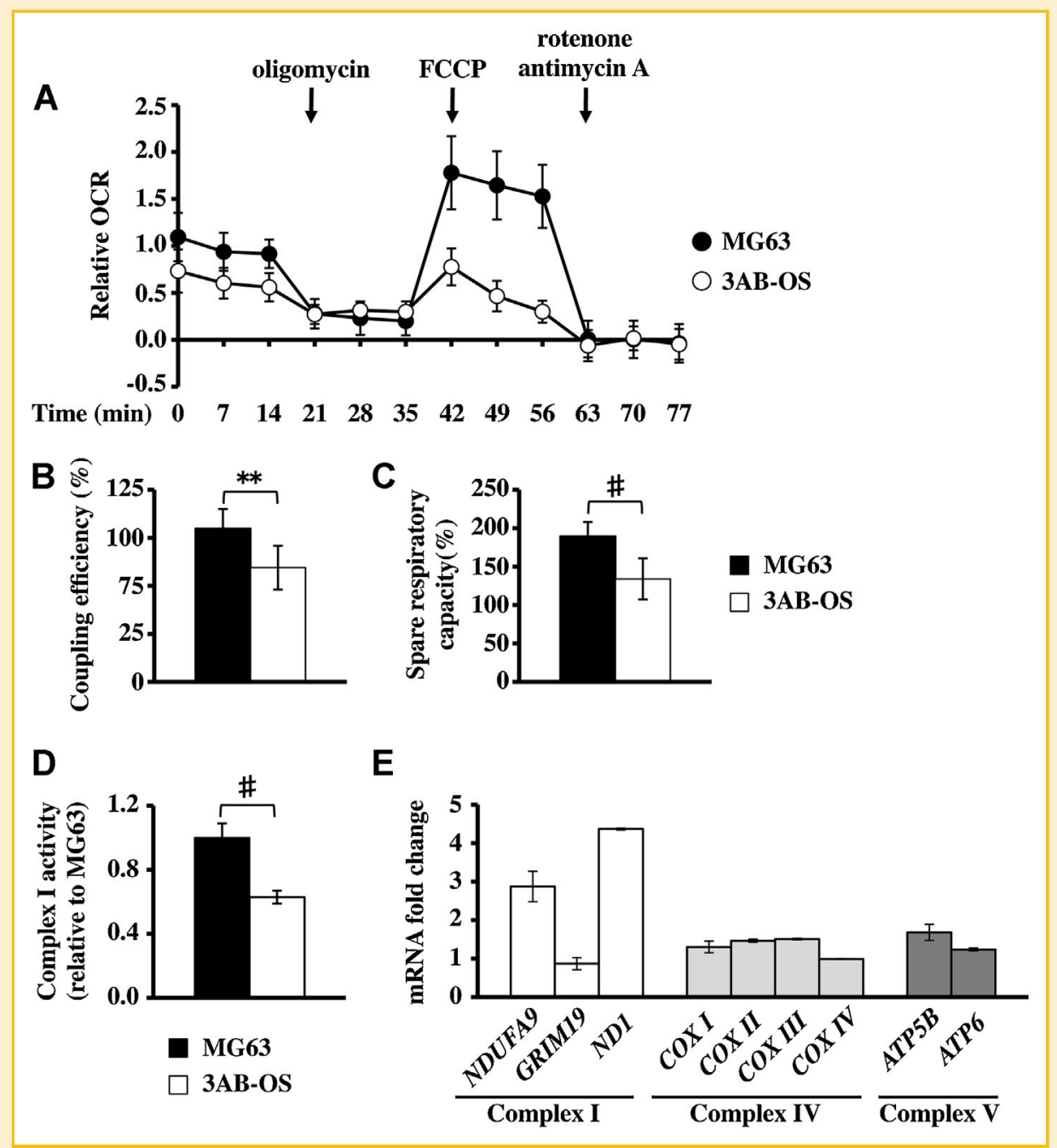

Fig. 4. $3 A B-O S$ have lower oxygen consumption rate and Complex I activity as compared to MG63. A: Oxygen consumption rate (OCR) was determined by Seahorse XF24 Extracellular Flux Analyzer, as described in Materials and Methods Section, under basal conditions and after adding oligomycin, FCCP and rotenone plus antimycin A (as indicated by the arrows). The coupling efficiency (B) and the spare respiratory capacity (C) were calculated for each sample by using the OCR values generated by Seahorse dedicated software. All data represent the average of three independent experiments and 15 total samples ( \pm SEM); ${ }^{* *} P<0.01$ and ${ }^{\#} P<0.001$ (Student's $t$-test). D: Complex I activity was measured in whole protein extracts of MG63 and $3 A B-O S$ and plotted as relative to the value obtained in MG63 cells. Data represent the average of three independent experiments ( \pm SD); ${ }^{\#} P<0.001$ (Student's $t$-test). E: Analysis of genes encoding respiratory chain subunits in $3 A B-0 S$ and MG63 cells were determined by real-time $q P C R$ using beta-actin $m R N A$ as an internal control. Levels of expression in $3 A B O S$ cells are reported as change ( $n$-fold) with respect to the amount of relative mRNAs expressed in MG63 cells. Data represent the average of three independent experiments $( \pm S D)$.

slight reduction of networked mitochondria, while in low glucose they showed a completely disappearance of fragmented mitochondria in favor of more interconnected mitochondria (Fig. 5B). Similar analyses in $3 \mathrm{AB}-0 \mathrm{~S}$ cells indicated a completely opposite behavior. In fact, at an early growth time (0-24 h), 3AB-0S displayed especially fragmented mitochondria (Fig. $5 \mathrm{C}$ ). At the later growth time (72 h), in glucose-rich medium, intermediate and networked mitochondria increased (Fig. 5C), while in low glucose these structures were almost lost with a parallel increase of fragmented mitochondria (Fig. 5C, right panel). Taken together, these results further confirm the differences between these two cell lines regarding mitochondrial function, and highlight the inability of $3 \mathrm{AB}-\mathrm{OS}$ cell mitochondria to elongate under glucose starvation.

\section{DISCUSSION}

We have sought to define the energetic metabolism of the CSC-like line, 3AB-0S, as compared to its osteosarcoma cancer cells of origin, MG63. It is interesting to note that MG63 cells have both mature and immature osteoblastic features [Pautke et al., 2004]. We started our analysis by measuring their ability to proliferate and survive in low glucose or glutamine availability, since both nutrients have been shown to be necessary for cancer cell proliferation and survival [Chiaradonna et al., 2006b; Yuneva et al., 2007; Palorini et al., 2013]. In addition, recent reports have shown that human pluripotent stem cells rely mostly on glycolysis to meet their energy demands [Chen et al., 2010; Prigione et al., 2010] and that osteogenic differentiation 


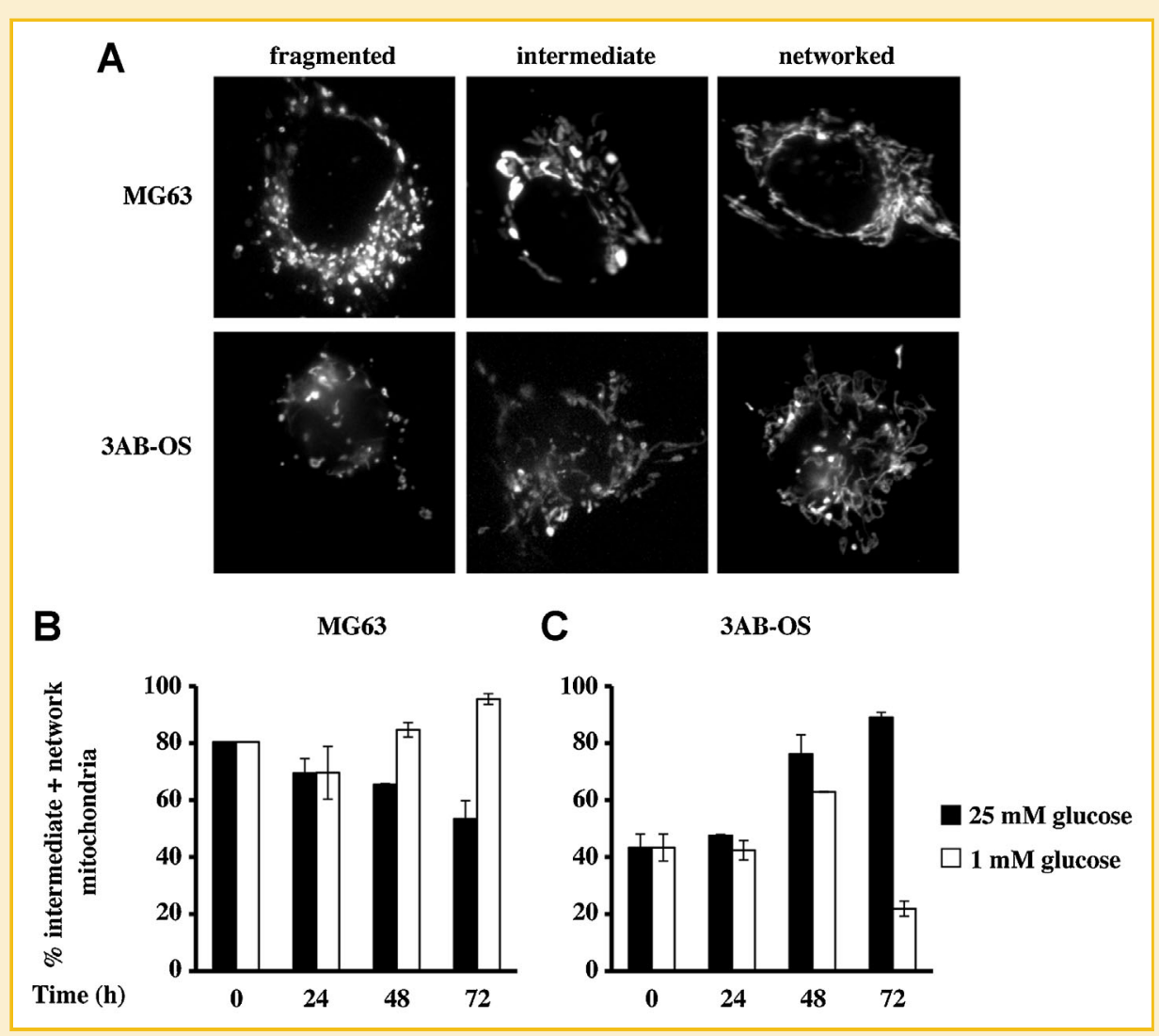

Fig. 5. $3 A B-O S$ cells upon glucose depletion are unable to network mitochondria. A: Examples of fragmented, intermediate and networked mitochondria in stable EYFP-Mito expressing MG63 (upper panels) and 3AB-OS cells (lower panels). B,C: Analysis of mitochondrial morphology in MG63 (B) and $3 A B-0 S$ (C) cells grown at 25 and 1 mM glucose for $72 \mathrm{~h}$. For each determination, at least 100 cells were counted and classified depending their mitochondrial morphology. Data represent the average of at least three independent experiments $( \pm \mathrm{SD})$.

of human mesenchimal stem cells (hMSCs) is characterized by an increase in the respiratory activity [Sanchez-Arago et al., 2013]. Our results clearly indicate that $3 \mathrm{AB}-\mathrm{OS}$ cells have an energetic metabolism similar to cancer cells and pluripotent stem cells and different to the osteosarcoma cancer cells of origin MG63. Indeed when they are subjected to glucose deprivation, they first undergo cell proliferation arrest, as observed in MG63 cells, and then, upon prolonged glucose starvation, cell death. Of interest is the fact that both cell lines, when grown in $25 \mathrm{mM}$ glucose, consume a similar amount of glucose per cell. Despite these results, $3 \mathrm{AB}-0 \mathrm{~S}$ accumulate a larger amount of lactate in the external medium, implying a more fermentative consumption of glucose as compared to MG63 cells. These observations, therefore, suggest that MG63 cells are more able to use glucose or other substrates through mitochondrial OXPHOS than fermentative glycolysis. In accordance, upon glutamine shortage the proliferation of MG63 is slightly inhibited. The elevated glycolysis in $3 \mathrm{AB}-0 \mathrm{~S}$ cells is confirmed by the higher expression of the essential glycolytic enzyme LDHA and by the observation that LDHA inhibition significantly induces $3 \mathrm{AB}-0 \mathrm{~S}$ cell death. Notable, as indicated before, despite a stronger dependence of $3 \mathrm{AB}-0 \mathrm{~S}$ cells from glucose availability, the rate of glucose uptake in this cell line is slightly lower as compared to MG63 cells. This result is in part unexpected taking in consideration that several reports have shown an increased expression of glucose transporters and glucose uptake in cancer cells [Rodriguez-Enriquez et al., 2009]. However, these findings are in agreement with a previously published transcriptional profiling analysis performed in MG63 and 3AB-OS cells grown in $25 \mathrm{mM}$ glucose [Di Fiore et al., 2013]. In fact, it has been shown a down-regulation of two glucose transporters, namely SLC2A10 and SLC2A12, in 3AB-OS cells as compared to MG63 [Di Fiore et al., 2013]. Therefore, despite a higher expression of GLUT1 in $3 \mathrm{AB}-0 \mathrm{~S}$ cells, we cannot exclude that other glucose transporters are more expressed in MG63 cells. Additionally reduced glucose consumption in lung CSCs as compared to lung cancer cells [Ye et al., 2011] or lower fluorodeoxyglucose (FDG) uptake in osteosarcoma stem cell-like line compared to its parental osteosarcoma cell line [Martins-Neves et al., 2012] has been also observed. This effect has been suggested to be consequent either to a reduced energy requirement of more quiescent cells, like stem cells, or to a more undifferentiated state, since glucose consumption and FDG uptake increase when they have been cultured in a differentiation medium [Ye et al., 2011; Martins-Neves et al., 2012]. Moreover, from our data we can argue that the main difference between the two cell lines is not the rate of glucose uptake but its fermentative fate through glycolysis 
in 3AB-OS cells and its greater respirative fate through OXPHOS in MG63 cells. These data are supported also by the reduced respirative metabolism of $3 \mathrm{AB}-0 \mathrm{~S}$ cells as compared to MG63. Indeed, growth on more respiratory substrates like galactose and pyruvate as well as the low effect on intracellular ATP levels of oligomycin and rotenone, known mitochondrial inhibitors, indicate a higher dependence on glycolysis as compared to MG63 cells. Additionally, the reduced oxygen consumption rate of $3 \mathrm{AB}-0 \mathrm{~S}$ cells and the significant reduction of Complex I activity convincingly imply that also this CSC like line has a metabolism similar to SCs. In fact, as described in the first section, it has been shown that repression and activation of the mitochondrial functions are critical for the self-renewal and differentiation of hESCs, respectively. Various authors have shown that ESCs before spontaneous differentiation, or as compared to differentiated cardiomyocytes, show a lower mitochondrial mass, a lower mtDNA copy number as well as lower ATP content [FacuchoOliveira et al., 2007; Facucho-Oliveira and St John, 2009; Hom et al., 2011]. Similar evidence has been observed also in HSC and MSC. Indeed the former cells show a reduced amount of mitochondria and low mitochondrial respiration [Piccoli et al., 2005] while the latter show a higher dependence on glycolysis for energy but rapidly shift to aerobic mitochondrial metabolism once they are induced to undergo, that is, osteogenic differentiation [Chen et al., 2008]. In this scenario, our findings assume an important meaning considering that undifferentiated pluripotent stem cells, which preserve their ability to renew themselves, show an anaerobic metabolism. Therefore, the ability in keeping a low energetic mitochondrial metabolism may also favor in cancer stem cells an undifferentiated state and the ability to renew. These are fundamental characteristics associated with their high tumorigenic potential [Kelly et al., 2007]. Despite the reduced mitochondrial activity, 3AB-OS cells showed a higher expression of mitochondrial genes encoding for Complex I subunits, namely NDUFA9 and ND1. This result was in part unexpected since previous data obtained in ESCs as well as in lung cancer-stem like cells have shown in both cells a reduced amount of mtDNA as compared to differentiated cells or A549 cancer cells, respectively [Cho et al., 2006; Ye et al., 2011]. However, recently, also other authors have observed that pluripotent cells present higher protein levels of mitochondrial complexes than differentiated cells, although they show a lower OXPHOS activity and rely mostly on glycolysis to meet their energy demands [Varum et al., 2011]. Moreover, Warburg effect in cancer cells is often accompanied by the lack of functional or well-assembled Complex I as consequence of point-mutations or mRNA expression deregulation in the genes encoding for subunits of this complex [Faure Vigny et al., 1996; Baracca et al., 2010]. Nevertheless, it has been also demonstrated that mtDNA mutations compromising both activity and assembly of OXPHOS complexes may decrease or even inhibit tumor growth in xenograft models [Park et al., 2009; Gasparre et al., 2011]. Given our results and the fact that the mechanisms leading to metabolic rewiring in CSCs remain largely unknown, we cannot exclude that such an increased expression would favor aerobic glycolysis. In the future further studies are needed, in particular it will be necessary to compare 3AB-OS cells to other osteosarcoma cell lines, that is, U2OS as well as to ESCs. On the other hand, morphological analysis of $3 \mathrm{AB}-\mathrm{OS}$ mitochondria, at the normal growth condition, indicated that they were more fragmented and perinuclear distributed as compared to MG63 cells. This result further supports a reduced mitochondrial activity, since such a morphology has been observed in ESCs, iPSCs, CSCs, and in several glucoseaddicted cancer cells, which are all characterized by OXPHOS impairment [Chiaradonna et al., 2006a; Mandal et al., 2011; Ye et al., 2011; Palorini et al., 2013]. Notable is that such an immature morphology evolves into filamentous networks of elongated and branched mitochondria when stem cells undergo differentiation [Mandal et al., 2011]. Our data indicated that 3AB-OS cells changed spontaneously mitochondrial morphology, increasing the percentage of more interconnected mitochondria, when grown in optimal conditions for at least $72 \mathrm{~h}$. Since this observation could suggest a partial spontaneous differentiation of $3 \mathrm{AB}-0 \mathrm{~S}$, in the future it will be interesting to correlate mitochondrial morphology with staminal markers as 0CT4 or NANOG as well as to correlate mitochondrial activity with $3 \mathrm{AB}-0 \mathrm{~S}$ differentiation. In fact, it is worth noting that these cells, upon established protocols, may be induced to differentiate in different types of cells such as osteoblasts and adipocytes (unpublished observations). Moreover it has also been shown that in ESCs there is a link among mitochondrial function, proliferation and self-renewal. In fact, in these cells, the inhibition of the mitochondrial function induces a retard of the proliferation of self-renewing cells, which becoming more glycolysis-dependent express pluripotent markers at a level even higher than their normal counterparts [Mandal et al., 2011]. Therefore, up to now we cannot exclude that $3 \mathrm{AB}-0 \mathrm{~S}$ cells may partially sustain a mitochondrial function, perhaps for an anabolic more than an energetic purpose, to maintain their proliferation capacity. In conclusion, our data indicate that $3 \mathrm{AB}-\mathrm{OS}$ cells rely mostly on glycolysis for their proliferation, survival and ATP production. In addition we clearly show that these cells have a reduced mitochondrial function and different mitochondrial morphology as compared to MG63 cells. Altogether these data confirm that CSCs have an energetic metabolism similar to either normal tissue stem cells [Varum et al., 2011] or to high glycolytic cancer cells [Chiaradonna et al., 2012; Ward and Thompson, 2012]. A better definition of the differences between CSCs and cancer cells will help the development of novel therapeutic strategies.

\section{ACKNOWLEDGMENTS}

This work was supported by grants to F.C. from Italian Government (FAR) and Italian Ministry of Education, University and Research, MIUR (PRIN 2008, 2008P8BLNF) and grants to R.V. from MIUR (ex60\% 2007 and PRIN 2008, 2008P8BLNF). R.P. has been supported by fellowships from MIUR (Fondo Giovani 2008) and Sysbionet. G.V. was supported by fellowship from Sysbionet. A.M. was supported by a fellowship from MIUR (PRIN 2008, 2008P8BLNF to R.V. and F.C.).

\section{REFERENCES}

Baracca A, Chiaradonna F, Sgarbi G, Solaini G, Alberghina L, Lenaz G. 2010. Mitochondrial Complex I decrease is responsible for bioenergetic dysfunction in K-ras transformed cells. Biochim Biophys Acta 1797:314-323.

Beug H. 2009. Breast cancer stem cells: Eradication by differentiation therapy? Cell 138:623-625.

Chen CT, Shih YR, Kuo TK, Lee OK, Wei YH. 2008. Coordinated changes of mitochondrial biogenesis and antioxidant enzymes during osteogenic 
differentiation of human mesenchymal stem cells. Stem Cells 26:960968.

Chen CT, Hsu SH, Wei YH. 2010. Upregulation of mitochondrial function and antioxidant defense in the differentiation of stem cells. Biochim Biophys Acta 1800:257-263.

Chen CT, Hsu SH, Wei YH. 2012. Mitochondrial bioenergetic function and metabolic plasticity in stem cell differentiation and cellular reprogramming. Biochim Biophys Acta 1820:571-576.

Cheng L, Alexander R, Zhang S, Pan CX, MacLennan GT, Lopez-Beltran A, Montironi R. 2011. The clinical and therapeutic implications of cancer stem cell biology. Expert Rev Anticancer Ther 11:1131-1143.

Chiaradonna F, Gaglio D, Vanoni M, Alberghina L. 2006a. Expression of transforming $\mathrm{K}$-Ras oncogene affects mitochondrial function and morphology in mouse fibroblasts. Biochim Biophys Acta 1757:1338-1356.

Chiaradonna F, Sacco E, Manzoni R, Giorgio M, Vanoni M, Alberghina L. 2006b. Ras-dependent carbon metabolism and transformation in mouse fibroblasts. Oncogene 25:5391-5404.

Chiaradonna F, Moresco RM, Airoldi C, Gaglio D, Palorini R, Nicotra F, Messa C, Alberghina L. 2012. From cancer metabolism to new biomarkers and drug targets. Biotechnol Adv 30:30-51.

Cho YM, Kwon S, Pak YK, Seol HW, Choi YM, Park do J, Park KS, Lee HK. 2006. Dynamic changes in mitochondrial biogenesis and antioxidant enzymes during the spontaneous differentiation of human embryonic stem cells. Biochem Biophys Res Commun 348:1472-1478.

Clarke MF, Becker MW. 2006. Stem cells: The real culprits in cancer? Sci Am 295:52-59.

Clarke MF, Dick JE, Dirks PB, Eaves CJ, Jamieson CH, Jones DL, Visvader J, Weissman IL, Wahl GM. 2006. Cancer stem cells-Perspectives on current status and future directions: AACR Workshop on cancer stem cells. Cancer Res 66:9339-9344.

Di Fiore R, Santulli A, Ferrante RD, Giuliano M, De Blasio A, Messina C, Pirozzi G, Tirino V, Tesoriere G, Vento R. 2009. Identification and expansion of human osteosarcoma-cancer-stem cells by long-term 3-aminobenzamide treatment. J Cell Physiol 219:301-313.

Di Fiore R, Guercio A, Puleio R, Di Marco P, Drago-Ferrante R, D'Anneo A, De Blasio A, Carlisi D, Di Bella S, Pentimalli F, Forte IM, Giordano A, Tesoriere G, Vento R. 2012. Modeling human osteosarcoma in mice through 3AB-OS cancer stem cell xenografts. J Cell Biochem 113:3380-3392.

Di Fiore R, Fanale D, Drago-Ferrante R, Chiaradonna F, Giuliano M, De Blasio A, Amodeo V, Corsini LR, Bazan V, Tesoriere G, Vento R, Russo A. 2013. Genetic and molecular characterization of the human osteosarcoma 3AB-OS cancer stem cell line: A possible model for studying osteosarcoma origin and stemness. J Cell Physiol 228:1189-1201.

Diehn M, Clarke MF. 2006. Cancer stem cells and radiotherapy: New insights into tumor radioresistance. J Natl Cancer Inst 98:1755-1757.

Facucho-Oliveira JM, St John JC. 2009. The relationship between pluripotency and mitochondrial DNA proliferation during early embryo development and embryonic stem cell differentiation. Stem Cell Rev 5:140-158.

Facucho-Oliveira JM, Alderson J, Spikings EC, Egginton S, St John JC. 2007. Mitochondrial DNA replication during differentiation of murine embryonic stem cells. J Cell Sci 120:4025-4034.

Faure Vigny H, Heddi A, Giraud S, Chautard D, Stepien G. 1996. Expression of oxidative phosphorylation genes in renal tumors and tumoral cell lines. Mol Carcinog 16:165-172.

Fillmore CM, Kuperwasser C. 2008. Human breast cancer cell lines contain stem-like cells that self-renew, give rise to phenotypically diverse progeny and survive chemotherapy. Breast Cancer Res 10:R25.

Gasparre G, Kurelac I, Capristo M, Iommarini L, Ghelli A, Ceccarelli C, Nicoletti G, Nanni P, De Giovanni C, Scotlandi K, Betts CM, Carelli V, Lollini PL, Romeo G, Rugolo M, Porcelli AM. 2011. A mutation threshold distinguishes the antitumorigenic effects of the mitochondrial gene MTND1, an oncojanus function. Cancer Res 71:6220-6229.

Gomes LC, Di Benedetto G, Scorrano L. 2011. During autophagy mitochondria elongate, are spared from degradation and sustain cell viability. Nat Cell Biol 13:589-598.

Ho MM, Ng AV, Lam S, Hung JY. 2007. Side population in human lung cancer cell lines and tumors is enriched with stem-like cancer cells. Cancer Res 67:4827-4833.

Hom JR, Quintanilla RA, Hoffman DL, de Mesy Bentley KL, Molkentin JD, Sheu SS, Porter GA, Jr. 2011. The permeability transition pore controls cardiac mitochondrial maturation and myocyte differentiation. Dev Cell 21:469-478.

Huang D, Gao Q, Guo L, Zhang C, Jiang W, Li H, Wang J, Han X, Shi Y, Lu SH. 2009. Isolation and identification of cancer stem-like cells in esophageal carcinoma cell lines. Stem Cells Dev 18:465-473.

Kelly PN, Dakic A, Adams JM, Nutt SL, Strasser A. 2007. Tumor growth need not be driven by rare cancer stem cells. Science 317:337.

Kim CH, Han SI, Lee SY, Youk HS, Moon JY, Duong HQ, Park MJ, Joo YM, Park HG, Kim YJ, Yoo MA, Lim SC, Kang HS. 2007. Protein kinase C-ERK1/2 signal pathway switches glucose depletion-induced necrosis to apoptosis by regulating superoxide dismutases and suppressing reactive oxygen species production in A549 lung cancer cells. J Cell Physiol 211:371-385.

Mandal S, Lindgren AG, Srivastava AS, Clark AT, Banerjee U. 2011. Mitochondrial function controls proliferation and early differentiation potential of embryonic stem cells. Stem Cells 29:486-495.

Martins-Neves SR, Lopes A0, do Carmo A, Paiva AA, Simoes PC, Abrunhosa AJ, Gomes CM. 2012. Therapeutic implications of an enriched cancer stem-like cell population in a human osteosarcoma cell line. BMC Cancer 12:139.

Mitra K, Wunder C, Roysam B, Lin G, Lippincott-Schwartz J. 2009. A hyperfused mitochondrial state achieved at G1-S regulates cyclin E buildup and entry into S phase. Proc Natl Acad Sci USA 106:11960-11965.

0'Brien CA, Kreso A, Jamieson CH. 2010. Cancer stem cells and self-renewal. Clin Cancer Res 16:3113-3120.

Palorini R, De Rasmo D, Gaviraghi M, Danna LS, Signorile A, Cirulli C, Chiaradonna F, Alberghina L, Papa S. 2013. Oncogenic K-ras expression is associated with derangement of the cAMP/PKA pathway and forskolinreversible alterations of mitochondrial dynamics and respiration. Oncogene 32:352-362.

Park JS, Sharma LK, Li H, Xiang R, Holstein D, Wu J, Lechleiter J, Naylor SL, Deng JJ, Lu J, Bai Y. 2009. A heteroplasmic, not homoplasmic, mitochondrial DNA mutation promotes tumorigenesis via alteration in reactive oxygen species generation and apoptosis. Hum Mol Genet 18:1578-1589.

Pautke C, Schieker M, Tischer T, Kolk A, Neth P, Mutschler W, Milz S. 2004 Characterization of osteosarcoma cell lines MG-63, Saos-2 and U-2 OS in comparison to human osteoblasts. Anticancer Res 24:3743-3748.

Piccoli C, Ria R, Scrima R, Cela 0, D'Aprile A, Boffoli D, Falzetti F, Tabilio A, Capitanio N. 2005. Characterization of mitochondrial and extra-mitochondrial oxygen consuming reactions in human hematopoietic stem cells. Novel evidence of the occurrence of $\mathrm{NAD}(\mathrm{P}) \mathrm{H}$ oxidase activity. J Biol Chem 280:26467-26476.

Prigione A, Adjaye J. 2010. Modulation of mitochondrial biogenesis and bioenergetic metabolism upon in vitro and in vivo differentiation of human ES and iPS cells. Int J Dev Biol 54:1729-1741.

Prigione A, Fauler B, Lurz R, Lehrach H, Adjaye J. 2010. The senescencerelated mitochondrial/oxidative stress pathway is repressed in human induced pluripotent stem cells. Stem Cells 28:721-733.

Qiang L, Yang Y, Ma YJ, Chen FH, Zhang LB, Liu W, Qi Q, Lu N, Tao L, Wang XT, You QD, Guo QL. 2009. Isolation and characterization of cancer stem like cells in human glioblastoma cell lines. Cancer Lett 279:13-21.

Rambold AS, Kostelecky B, Elia N, Lippincott-Schwartz J. 2011. Tubular network formation protects mitochondria from autophagosomal 
degradation during nutrient starvation. Proc Natl Acad Sci USA 108:1019010195.

Rodriguez-Enriquez S, Marin-Hernandez A, Gallardo-Perez JC, MorenoSanchez R. 2009. Kinetics of transport and phosphorylation of glucose in cancer cells. J Cell Physiol 221:552-559.

Sanchez-Arago M, Garcia-Bermudez J, Martinez-Reyes I, Santacatterina F, Cuezva JM. 2013. Degradation of IF1 controls energy metabolism during osteogenic differentiation of stem cells. EMBO Rep 14:638-644.

Sandulache VC, Ow TJ, Pickering CR, Frederick MJ, Zhou G, Fokt I, DavisMalesevich M, Priebe W, Myers JN. 2011. Glucose, not glutamine, is the dominant energy source required for proliferation and survival of head and neck squamous carcinoma cells. Cancer 117:2926-2938.

Tang C, Ang BT, Pervaiz S. 2007. Cancer stem cell: Target for anti-cancer therapy. FASEB J 21:3777-3785.

Varum S, Momcilovic 0, Castro C, Ben-Yehudah A, Ramalho-Santos J, Navara CS. 2009. Enhancement of human embryonic stem cell pluripotency through inhibition of the mitochondrial respiratory chain. Stem Cell Res 3:142-156.

Varum S, Rodrigues AS, Moura MB, Momcilovic 0, Easley CA, RamalhoSantos J, Van Houten B, Schatten G. 2011. Energy metabolism in human pluripotent stem cells and their differentiated counterparts. PLoS ONE 6: e20914.
Ward PS, Thompson CB. 2012. Metabolic reprogramming: A cancer hallmark even warburg did not anticipate. Cancer Cell 21:297-308.

Westermann B. 2010. Mitochondrial fusion and fission in cell life and death. Nat Rev Mol Cell Biol 11:872-884.

Ye XQ, Li Q, Wang GH, Sun FF, Huang GJ, Bian XW, Yu SC, Qian GS. 2011. Mitochondrial and energy metabolism-related properties as novel indicators of lung cancer stem cells. Int J Cancer 129:820-831.

Yuneva M, Zamboni N, Oefner P, Sachidanandam R, Lazebnik Y. 2007. Deficiency in glutamine but not glucose induces MYC-dependent apoptosis in human cells. J Cell Biol 178:93-105.

Zhang J, Khvorostov I, Hong JS, Oktay Y, Vergnes L, Nuebel E, Wahjudi PN, Setoguchi K, Wang G, Do A, Jung HJ, McCaffery JM, Kurland IJ, Reue K, Lee WN, Koehler CM, Teitell MA. 2011. UCP2 regulates energy metabolism and differentiation potential of human pluripotent stem cells. EMBO J 30:48604873.

\section{SUPPORTING INFORMATION}

Additional supporting information may be found in the online version of this article at the publisher's web-site. 